\title{
La música fusión, ¿verdadera inclusión? Una exploración de la escena fusión en Lima
}

\section{Fiorella Montero-Díaz}

Universidad de Keele

r.montero.diaz@keele.ac.uk

RESUMEN

En los últimos años, la fusión intercultural en Lima ha ido creciendo hasta convertirse en un género musical «nacional» portador $y$ visibilizador de interacciones intersociales e interétnicas, las cuales retan la segregación cultural sistemática de la sociedad peruana. Esta música brinda espacios donde los jóvenes de clases altas tradicionales retan sus roles históricos antagonistas y buscan la trascendencia cultural y el significado espiritual, con el fin de hallar sus propias tradiciones culturales, un concepto propio de lo sagrado y de ellos mismos.

Este artículo, basado en diversos estudios de caso, explora los discursos - a veces contradictorios - que emplean los músicos de fusión (de clase alta tradicional o no) al describir su música, así como los temas que ellos resaltan como trascendentales para compartir con su público de clase alta tradicional a través de sus proyectos musicales. Luego, examinará el potencial de esta música fusión como herramienta para facilitar las interacciones creativas interétnicas e interclase, a través de las cuales los jóvenes de clases altas tradicionales pueden recrear su «yo» y autoincluirse en una narrativa de país más plural y menos exclusiva. Finalmente, documentará cómo los músicos de fusión retan las ya normalizadas percepciones e imaginarios sociales de las clases altas tradicionales mediante la creación de diálogos musicales. Analizará cómo 
el hecho de entender la diferencia mediante la música facilita la búsqueda de su propio yo político y espiritual, lo cual les permite trascender la música y subvertir su propia identidad de clase para así experimentar una Lima «más real», un «nuevo Perú».

Palabras clave: fusión musical peruana, hibridación, clases altas tradicionales, diálogos musicales, identidad de clase, juventud urbana.

\section{Fusion as inclusion: Just a delusion? An exploration of Lima's fusion scene} ABSTRACT

In recent years, intercultural popular fusion music in Lima has grown into a representative «national» genre where intersocial and interethnic interactions take place challenging the established segregation of Peruvian society. This music seems to provide a space where youths contest their historical antagonistic role in Lima looking for cultural transcendence and spiritual meaning, searching for their own popular tradition, their own sacred, themselves.

Based on diverse case studies, this article explores the sometimes contradictory discourses of fusion musicians when describing their music, as well as the issues they highlight as important to address through their intercultural projects. Moreover, it will examine the potential of fusion music as a means to enable interclass and interethnic interactions, in which the young white upper classes seek to recreate «the self» and include themselves in their own country. Finally, it will document how fusion musicians challenge normalized perceptions and social class imaginaries through the creation of music dialogues. It will explore how the understanding of difference through musicking enables them to search for their own political and spiritual self, which in turn allows them to transcend music and subvert their own class identity in order to experience the "real» Lima, the «New Peru».

Keywords: Peruvian fusion music, hybridization, traditional upper classes, music dialogues, class identity, urban youth. 
La hibridación musical es un tema que me apasiona, y por ende llevo ya ocho años de mi carrera académica explorando la fusión musical peruana. He conversado con más de un centenar de los que conforman esta escena limeña, entre músicos y audiencias, productores, representantes de venta, sellos discográficos, ingenieros de sonido, agentes y otros. Mi enfoque principal es el estudio del público y los músicos de las clases altas tradicionales limeñas, en particular los jóvenes y adultos jóvenes (18-35 años), y su uso de la fusión musical como herramienta de discusión social, facilitadora de nuevos gustos y estéticas, y como posible tecnología de transformación de conflictos ${ }^{1}$; en el caso peruano, conflictos de clase, raza y etnia exacerbados por el conflicto armado interno ${ }^{2}$. En pocas palabras, escribo sobre la música y las clases sociales altas o élites en un contexto de postguerra o postconflicto.

Los términos élite o élites tradicionales se usan aquí para referirse a los grupos de poder más ricos que aún se perciben como blancos y pertenecen a familias con apellidos de renombre de procedencia extranjera o española asociados con la historia política y el desarrollo industrial del Perú. Algunos aún mantienen su poder económico, otros solo el estatus que les da el apellido y la «blanquitud». El término clases altas tradicionales agrupa también a las élites tradicionales, pero incorpora a los estratos socioeconómicos altos (mas no de élite), que también se perciben como blancos y se consideran parte de la Lima criolla. Cabe resaltar que también existen clases altas provincianas, indígenas y emergentes, pero no se consideran en esta investigación, que se centra en las clases altas tradicionales limeñas. Reconozco que estos términos son problemáticos, ya que pueden reforzar la segregación social a partir de etiquetas y divisiones recreadas por variables económicas y sociales, sin embargo; sirven para distinguir a los jóvenes insertados en familias que han pertenecido a las clases altas tradicionales por generaciones de los jóvenes pertenecientes a los nuevos grupos emergentes de poder.

2 En algunos casos me referiré a ideas e imaginarios raciales y no étnicos, ya que la etnicidad es percibida como una categoría que se escoge y a la cual se pertenece por elección y la raza es percibida como una categoría que no se escoge (p.e., fenotipo, color de piel) (Radano y Bohlman, 2000, p. 8). 
Cabe resaltar que mi investigación no abarca toda la clase alta. Como sabemos, las clases altas también son diversas y no pueden reducirse a un solo bloque con las mismas características. Yo observo a los jóvenes limeños de clase alta tradicional, que principalmente se identifican con las tendencias políticas de izquierda moderada, son liberales, por lo general rechazan nociones de exclusividad y superioridad y expresan un grado de compromiso social. En el argot limeño, se refiere a menudo a este grupo de jóvenes como «pezuñentos», «hippies», «barrancoides» o «progres». Yo prefiero llamarlos alternativos, ya que este término no tiene una carga peyorativa ni es una caricatura de sus estilos de vida.

La fusión musical luego de 2006, postconflicto interno, y el restablecimiento de los circuitos musicales, sirvió para marcar la identidad alternativa de estos jóvenes y diferenciarse, a través de un involucramiento musical distinto, de los jóvenes de clases altas que guardan su distancia de lo vernacular aduciendo un «consumo refinado, de buen gusto y exclusivo». La fusión a la que me refiero generalmente mezcla música tradicional andina, afroperuana o amazónica con estéticas urbanas más foráneas, y así representa la valoración de géneros musicales, estéticas y músicos previamente marginalizados por las clases altas por su procedencia y gusto, junto con sus respectivas cosmovisiones y lenguas (p.e., quechua) $)^{3}$.

Durante mi trabajo de campo (2010-2011) he colaborado con varios músicos clasificados en el género de fusión por las audiencias que los siguen. Algunos de estos músicos provienen de las clases altas tradicionales y muchos de ellos son fundadores o integrantes de bandas musicales interclase e interraciales. Algunos se autoidentifican como fusionistas; otros piensan que el término fusión describe diálogos musicales fríos, exotistas y fabricados, y otros tantos, aunque insisten en no estar haciendo música fusión, promueven sus creaciones como tales (p.e., Bareto ${ }^{4}$, Novalima ${ }^{5}$, La Mente ${ }^{6}$ ).

Para más información sobre la fusión musical en Lima ver Montero-Díaz, 2016, pp. 192-193. En una antigua versión de su previa página web (2010), Bareto combinaba el nombre de la banda con la palabra fusión. Algunos hasta creían que el nombre del grupo era «Bareto Fusión» en vez de Bareto.

5 En la página oficial de Facebook de Novalima dicen: «En su álbum de 2009—Coba Coba-, Novalima continúa con la fórmula aplaudida por los críticos que desarrolló en sus dos previas grabaciones, a la vez que dirige su fusión inspiradora por nuevos y emocionantes senderos» (traducido del inglés por la autora). https://www.facebook.com/pg/novalima.official/ about/?ref=page_internal (Visitado agosto 2016).

6 En el artículo «Se le salió el indio», publicado en 2010 por Descabellado Discos del Perú, estudio de grabación y compañía de producción fundada por La Mente, se dice: «Las melodías de los saxos caminan de la mano de los teclados, clásicos y modernos, como en una procesión 
En este artículo examinaré los discursos, a veces contradictorios, que emplean los músicos de fusión (de clase alta tradicional o no) al describir su música, así como los temas que ellos resaltan como trascendentales para compartir con su público de clase alta tradicional a través de sus proyectos musicales. Luego, con el apoyo teórico de la literatura de análisis del World Music, examinaré el potencial de esta música fusión como herramienta para facilitar las interacciones creativas interétnicas e interclase, a través de las cuales los jóvenes de clases altas tradicionales pueden recrear su yo y autoincluirse en una narrativa de país más plural y menos exclusiva. Finalmente, documentaré cómo los músicos de fusión retan las ya normalizadas percepciones e imaginarios sociales de las clases altas tradicionales mediante la creación de diálogos musicales. Analizaré cómo el hecho de entender la diferencia mediante la música facilita la búsqueda de su propio yo político y espiritual, lo cual les permite trascender la música. Espero, con este artículo, contribuir al análisis etnográfico y crítico de cómo la fusión musical se encuentra, para muchos músicos y públicos, dentro de un límite algo borroso entre ideales optimistas inclusivos, íntimas reflexiones del otro y el yo, el exotismo y la apropiación cultural.

\section{EL DILEMA DEL MÚSICO DE FUSIÓN PERUANO}

Para algunos académicos, la fusión intercultural refuerza la diferencia en vez de celebrarla ${ }^{7}$. Además, contribuye a la idea del mestizaje como asimilación del andino y, por ende, a la desaparición de la cultura tradicional, es decir «lo híbrido puede ser hegemónico» (Ritter, 2011, p. 573). Para otros estudiosos - y algunos limeños - , la fusión valida ideas ingenuas y pasajeras de unión social, mas no soluciona la segregación imperante (Alfaro en Kisner, 2008; Tucker, 2013). Sin embargo, la fusión musical también puede promover resistencia política activa contra la segregación étnica, racial y de clase, la discriminación, el abuso de poder y la desigualdad social (Montero-Díaz, 2016). En otras palabras, lo híbrido también puede ser antihegemónico.

andina que atraviesa el trópico, y las secuencias electrónicas son más ahorrativas e inteligentes que en el disco anterior. En este disco cuajó el sonido y la propuesta en general de esa fusión (aunque la palabra duela) de música primigenia y sonido futurista. http://descabelladodiscos. blogspot.co.uk (Visitado agosto 2016).

7 Música fusión intercultural, en este contexto, es música que presenta una interacción armónica, democrática y respetuosa de diferentes culturas, lenguas e individuos, visibilizando la diferencia cultural y celebrándola en el escenario. 
El público de fusión define la música de sus artistas como fusión, pero para algunos músicos es un término incómodo asociado con la proliferación del World Music mundial, la apropiación y la explotación de poblaciones indígenas, así como colectivos y compositores de países de ingresos bajos ${ }^{8}$. En el trabajo de campo, cuando les pregunté si clasificarían su música como fusión, solo cinco de 37 grupos/músicos procedentes de diversas clases sociales y categorizados por su público como fusionistas describieron su música como un género fuera del marco fusión. Usaron, en lugar de ello: «rock con sentimiento andino», «rock del nuevo Perú», «música peruana contemporánea»o «nueva música afroperuana». Algunos músicos también dijeron que la fusión en su música era «natural», algo que era de esperarse dado el desarrollo social de la Lima contemporánea. Pero, ¿qué tiene de «natural» la música fusión peruana? La mitad de los músicos entrevistados remarcaron la multiculturalidad en el Perú, y presentaron a Lima como un crisol de peruanos de diferentes experiencias culturales y sociales, lo cual genera «gente fusionada». Por ejemplo, Damaris Mallma, nacida en los Andes pero residente actual de Lima, opina que su música es un producto natural de su identidad dual. Lo mismo pasa con Lucho Quequezana, quien nació en Lima, pero pasó su infancia en los Andes. Ellos se muestran orgullosos de su identidad mezclada y no sienten la necesidad de evidenciar diferencias culturales, ya que piensan que Lima es tan diversa que al final «todos son iguales». Este argumento es similar a las ideas del etnomusicólogo brasileño Mario de Andrade (1928) de fomentar unidad nacional a través de una música donde el negro, el blanco y el indio puedan vencer sus imaginarios étnicos (ver Stokes, 1994, p. 14).

Ahora, no solo los músicos con experiencias de vida multiculturales discuten la unidad y la igualdad en sus obras. Nicolás Duarte, de La Mente, opina que «cuando no puedes hacer otra cosa [creativamente] y lo que te sale es esto [fusión], no es que tú estés fusionando, sino que estás fusionado». Esta es una de las razones por las que los músicos piensan que la fusión no es un género creado, sino uno que surge espontáneamente, y valoran las mezclas que no se sienten prefabricadas y que no son netamente comerciales. Otros músicos de clase alta tradicional, como los de Bareto y Colectivo Circo Band, a través de sus letras, presencia escénica y estéticas interculturales, desafían las nociones de gusto refinado, foráneo o la supuesta superioridad artística de los blancos de clase alta.

8 Este fenómeno no es propio de la hibridación en el Perú. Otros académicos han discutido las apropiaciones culturales para el mercado global de grupos como Deep Forest (Feld, 2000b, 1996, pp. 24-26; Stokes, 2004, pp. 57-58) y Enigma (Stokes, 2004, p. 56; Hesmondhalgh, 2000; Taylor, 2003). 
A pesar de que la colaboración intercultural no se resalte en el escenario, buscan activamente el contacto entre diferentes culturas y clases sociales, convirtiéndolo en índices mediante los géneros interpretados (cumbia, huayno, entre otros), la procedencia de los integrantes de las bandas, los invitados a sus conciertos y la diversidad de su público objetivo.

Sin embargo, no todos los músicos basan sus fusiones en la convivencia o el diálogo intercultural. Algunos músicos, generalmente mayores de cuarenta años, realzan el diálogo estético y la exploración de sonoridades diferentes, pero no necesariamente con la gente que los produce. Para los fusionistas que buscan involucrarse más con las culturas que forjan las diferentes estéticas, estos son intentos superficiales exotistas, pero coinciden en afirmar que aun así visibilizan estéticas andinas en los circuitos de clase alta, estratos que no solían prestar atención a dichas estéticas ni valorarlas. Para un buen número de los músicos de fusión en Lima, la clave para evitar el exotismo y romantizar al otro es establecer interacciones humanas a través de la música. No obstante, surgen algunas contradicciones:

Imagínate pues, Serenata de los Andes from Perú [en inglés]; me tengo que inventar ahorita un término que llegue universalmente, por decirte «el misterio de los Andes» o «la música del misterio de los Andes» [...] puede empezar con una proyección de un chamán en negro que hable en quechua [imita el sonido del quechua] y ahí empezamos con el primer tema [tararea el primer tema de su disco]. Hay un gran potencial del Perú por el colorido, misterio, ruinas, por eso es que está lleno de turistas pues, por el misterio del Perú (Jean Pierre Magnet, entrevista personal, octubre 2010) ${ }^{9}$.

Jean Pierre parece querer mostrar una imagen de los Andes misteriosos, místicos y exóticos. A la vez, trata de transformar la fusión musical en un producto para turistas, lo cual ya ha sido severamente criticado por muchos fusionistas. Sin embargo, estas mezclas forman parte de la escena fusión, y otros músicos y públicos disfrutan de esta música como experiencias estéticas temporales. Por otro lado, la música fusión de Bareto, La Sarita, Uchpa, entre otros — quienes muestran, cantan y escenifican diálogos interculturales y convivencia - atraen a públicos más diversos, incluyendo a una clase alta tradicional más joven que muestra un idealismo político a través de la celebración de la diversidad.

9 Todas las entrevistas que aquí se discuten las realizó la autora de este artículo durante su trabajo de campo en Lima en 2010-2011, salvo que se estipule lo contrario. 
Nicolás Duarte, de La Mente, percibe la colaboración de su grupo con la artista vernacular Laurita Pacheco y una tropa de sicuris como una forma de hacer que su público «sienta a través de la evocación que viene de lo que es tu infancia y de lo que es tu patria, una conexión» (Nicolás Duarte, entrevista personal, noviembre 2010), pero menciona a Laurita en la misma oración en la que habla de personajes de ficción:

Lo que nosotros sí empezamos a hacer con La Mente [fueron] cosas nuevas y distintas, entonces la idea era también ofrecer un espectáculo distinto. No solo poníamos sicuris: también teníamos a un pata que se disfrazaba de Alf y salía a bailar en el escenario. La gente no se acuerda de esto porque no es relevante para el momento de revalorización cultural que tenemos [...] se acuerdan de Laurita Pacheco y de los sicuris, pero no se acuerdan de Alf, no se acuerdan de Freddy Krueger, personajes que nosotros hemos sacado a bailar al escenario, porque es parte de lo que hemos vivido nosotros [...] yo de chico veía Alf, veía Los Magníficos, tú ves las propagandas de La Mente y todas están basadas en series y personajes de esa época, o sea El Auto Fantástico, La Pequeña Maravilla, sicuris y Laurita Pacheco (Nicolás Duarte, La Mente, entrevista personal, noviembre 2010).

Esta descripción de los músicos andinos siendo incluidos en conciertos al mismo estilo que personajes de ficción como Alf, Freddy Krueger y La Pequeña Maravilla es muy problemática. Podría interpretarse, sin embargo, como una nostalgia torpe que busca incluir aspectos asociados con el pasado individual, con la vivencia personal, como fueron otros iconos de la niñez, los cuales son marcadores de la misma etapa de consumo. Una invitación a vincular estos sonidos con imágenes añoradas de la niñez y así superar el rechazo sistemático. Nicolás, por ejemplo, en nuestras conversaciones mencionaba la música criolla que escuchaba su padrastro en casa y la chicha que escuchaba la empleada de su abuela en el cuarto de servicio ${ }^{10}$ como parte de los sonidos de su niñez. Algo que se escuchaba involuntariamente, sin mayor reflexión, y que luego se hizo parte de la razón para la exploración musical de su adultez. Estos son músicos que constantemente tratan de entender al país desde su posición de privilegio, y este proceso está lleno de contradicciones e incoherencias que ellos tratan de entender y negociar entre ellos y con su público.

10 Lo que inspiró la letra de «Radio Funeral». 
Los dilemas no existen solo entre músicos de las clases más acomodadas. Un músico andino de estudio opina:

Chamba es chamba, a mí me gusta fusionar, aunque a veces decepcione a los más antiguos en la tradición, tú sabes, la tradición es la tradición. Pero ¿por qué no puedo fusionar? Yo veo a los blancones haciendo esto, ¿por qué yo no? Creo que estos proyectos nos visibilizan, el tocar con los colorados nos valida. Ahora tocamos algo chévere, tenemos más trabajo. Ellos creen que nos hacen el favor, cuando realmente nosotros les sacamos provecho (Sergio ${ }^{11}$, entrevista personal, agosto 2010).

Me gustaría hacer hincapié en la frase «ellos creen que nos hacen el favor». Esta frase reta el discurso de «revaloración y rescate cultural» que algunos fusionistas han usado al promover su trabajo. Sin embargo, como muchos músicos andinos afirman, la música andina no necesita ser validada, rescatada ni revalorada (p.e., entrevistas personales a Chano Díaz Limaco, 2010; Chalena Vásquez, 2010, entre otros). Entonces, la pregunta realmente es ¿para quiénes la fusión rescata la tradición del olvido?

Nadie [de los músicos fusión] invita a Laurita Pacheco a tocar en sus conciertos, entonces para nosotros sirve porque es original, la reivindica a ella frente a un grupo de gente que no le ha dado la pelota que se merece, pero ella no necesita ser reivindicada por ese público ni mucho menos. Ella llena, y con mucho más éxito, plazas mucho más grandes que [aquellas] donde nosotros tocamos (Nicolás Duarte, La Mente, entrevista personal, noviembre 2010).

Nicolás advierte que La Mente no está rescatando la tradición vernacular. Ellos simplemente muestran esta tradición a un público que usualmente no ha valorado esta música ni a sus ejecutantes. Esto brinda a los estratos más altos la oportunidad de entrar en contacto con estéticas previamente estigmatizadas por su clase social. Pero Laurita no necesita a la clase alta tanto como la clase alta la necesita a ella para sentirse incluida en una Lima más plural y abierta, una Lima que trasciende Barranco, Miraflores y San Isidro.

El rol de las clases altas en la manipulación de las clases trabajadoras vía la invención de tradiciones culturales por razones políticas (Hobsbawm y otros, 1983), o la apropiación de entretenimiento popular para volverlo de consumo exclusivo (Storey, 2003, pp. 34-37) han sido ampliamente documentados.

11 A pedido de algunos colaboradores se han omitido algunos apellidos y sustituido nombres verídicos por seudónimos para así preservar el anonimato. En el caso de entrevistas hechas a miembros del público, se consigna el nombre y la edad del entrevistado. 
No obstante, estos académicos dan sus argumentos centrándose en la acción de robo o explotación de las clases bajas o subalternas. Yo arguyo, basada en la investigación de la música andina en Japón de Michelle Bigenho (2012) y la investigación de Zoila Mendoza sobre colaboraciones musicales entre mestizos e indígenas andinos (2008), que el acto de apropiación es mucho más que un marco simplista de interpretación de la hibridación, sino que es un proceso de dos vías en el cual se dan múltiples diálogos, interacciones y préstamos mutuos. Por ende, es necesario centrarnos en la interacción y relaciones que se forman en las apropiaciones multidireccionales. Así, podremos explorar los productos musicales de estos encuentros, los cuales en muchos casos generan curiosidad mutua y discusiones entre los músicos de fusión y su público sobre poder, ética, impacto y agencia, sin importar su procedencia de clase, raza o etnia. John Storey, en su libro Inventing Pop Culture (Inventando la cultura popular), sugiere:

[...] hace falta no solo comprender cómo la producción genera un repertorio de productos para el consumo, sino también comprender las muchas maneras en las que las personas hacen suyos, llenan de significado y utilizan estos productos, y así los convierten en cultura en las prácticas vividas de la vida cotidiana (2003, p. 55).

Steven Feld, en Sweet Lullaby for World Music (2000a), discute la dicotomía de los discursos - alarmistas, por un lado, y celebratorios, por otro- de la hibridación en la música del mundo. A su vez, afirma que, aunque estos discursos resaltan diferentes aspectos como la comodificación y el diálogo, respectivamente, ambos «aceptan la pluralidad musical como una necesidad dialéctica». Las teorías que celebran la hibridación, como las de George Lipsitz (1997) y Mark Slobin (1993), han sido criticadas por «exagerar el poder cultural y la visibilidad de la música ignorando hasta qué punto el poder y la visibilidad están estructurados por un complejo industrial cada vez más global» (Born y Hesmondhalgh, 2000, p. 27). Ahora, si bien las fuerzas del mercado global influyen en las músicas locales, dichas fuerzas no necesariamente impactan en la cultura local de una manera vertical, sino a través de procesos bilaterales de glocalización musical, y los fusionistas y los músicos andinos pueden «canibalizar» lo foráneo haciéndolo propio ${ }^{12}$. ¿Cómo se relacionan estos procesos con las motivaciones personales de los músicos a la luz de las políticas de identidad? ¿Es que somos testigos de un deseo de «intimidad intercultural» por la clase tradicional alta a través de la música? Sería una especie

12 Para leer más sobre el cosmopolitismo y la canibalización de lo foráneo, ver M. Stokes (2008) y F. Moehn (2012), respectivamente. 
de «distancia íntima», para utilizar el concepto de Michelle Bigenho (2012). El término de Bigenho ilustra la atracción y el deseo de aproximarse y hasta de encarnar al «otro diferente», mientras se mantiene una distancia «natural» (del yo al otro). En el Perú, esta distancia natural es compleja, ya que no es neutral, sino creada y cementada por los juicios de valor asociados con las diferencias y jerarquías imaginadas blanco-indígena, rico-pobre, occidental-andino, etc., en un mismo país, donde cada uno imagina su propia «peruanidad» a partir de las divisiones del pasado y presente. La fusión musical es una herramienta más para negociar esta «distancia natural», para reformularla desde la cotidianidad, y así re-imaginar una «peruanidad» distinta de aquella idea jerarquizada.

\section{ACERCAMIENTO AL OTRO, ACERCAMIENTO A UNO MISMO}

Para el antropólogo Efraín Rozas, en los proyectos de fusión peruana «hay una intención explícita en el artista por buscar un acercamiento al 'otro', en el plano de la intersubjetividad, a través del arte, de la creación» (2007, p. 41). Yo arguyo que algunas veces el acercamiento al otro no es el propósito principal de la música, sino la autorrecreación de uno mismo a través de la interacción con el otro (ver también Hopenhayn, 1999). Esta podría ser la razón por la cual algunos músicos de clase alta tradicional dicen que la motivación al fusionar (y también al ser público de fusión) es responder a preguntas como: ¿quién soy yo? ¿Cómo encajo en la ciudad y en el país? ¿Cuál es mi papel? La fusión se vuelve entonces una plataforma de investigación en la cual pueden interactuar con música que «no corresponde» a su fenotipo y estatus social y, por ende, «no puede ser de ellos»; una plataforma que les permite organizar y hacer música intercultural, interactuar con públicos de diversas clases socioeconómicas y sentirse como «todos los demás» en Lima.

Por ejemplo, en 2010 entrevisté a Joaquín Mariátegui en su casa en Miraflores cuando era el director musical de Bareto. Durante la entrevista se refería a sí mismo como «colorado» y siempre resaltó ser un «pituco alternativo»: «Yo, siendo pituco, nunca he ido a fiestas del Regatas, ni paro con la gentita, siempre he sido un poco alternativo» (Mariátegui, entrevista personal, 2010) ${ }^{13}$. Cuando Bareto lanzó su álbum Cumbia en 2008, la cumbia ya era popular, aún en los circuitos

13 Pituco es la palabra más común en Lima para referirse a las clases altas blancas. Es un término utilizado frecuentemente de manera peyorativa para englobar nociones de «blanquitud» y privilegio económico. 
de élite, pero era tocada por músicos de provincia, a quienes no se les recibía con el mismo calor que a su música. ¿Qué incita a un músico como Joaquín, blanco y con dinero, experto en otros géneros musicales más foráneos, a juntar músicos de diferentes clases sociales para crear una orquesta que vaya contra el paradigma de lo que una orquesta de cumbia «debe ser»?

Esa es la gran pregunta del peruano, pues, ¿qué somos? ¿Qué carajo somos? Eso a mí me pasaba [...] yo escuchaba reggae, escuchaba jazz y escuchaba rock, escuchaba funk... ¡Eso no es de acá huevón! O sea, yo caminaba por la calle y la combi no tiene nada que ver con James Brown, ¿me entiendes? $\mathrm{O}$ sea, un afilador de cuchillos no tiene nada que ver con Miles Davis [...]Yo creo que para mí la música se ha vuelto un instrumento para encontrarme en el mapa básicamente; la música para mí es como una brújula y a mí me dice quién soy (Joaquín Mariátegui, ex integrante de Bareto, entrevista personal, setiembre 2010).

Joaquín claramente sentía un conflicto entre su gusto musical más expuesto a lo foráneo y la realidad cotidiana de la ciudad. Nadie puede negar que las experiencias de Joaquín son peruanas y que él también lo es, pero ¿cómo puedes sentirte peruano si tu identidad es frecuentemente racializada como foránea y por ende se hace cada vez más ajena a la imagen que tienes de ti mismo? ${ }^{14}$. La fusión musical se vuelve entonces una herramienta para descubrirse a sí mismo y luego reconstruir el yo. En el caso de Joaquín, reconstruirse como un chichero «colorado» alternativo. Para él, tocar cumbia lo incluye en una experiencia peruana más amplia, la cumbia lo hace sentir autoincluido y menos antagónico. La cumbia es, pues, «lo que todo el mundo escucha» y él es ya parte de «ese mundo».

Todo el mundo escucha cumbia y escucha chicha, todo el mundo. En Ayacucho no escuchan festejo, pero sí escuchan huayno, en Cañete escuchan festejo, pero no escuchan huayno, pero todos escuchan chicha (Joaquín Mariátegui, ex integrante de Bareto, entrevista personal, setiembre 2010).

Es a través de la búsqueda de una experiencia compartida con otros en Lima que, en 2008, Bareto invita a Wilindoro Cacique, vocalista original de Juaneco y su Combo, a cantar con ellos en una serie de conciertos animados por el éxito

14 Racialización aquí se entiende como la atribución o asignación de características raciales al consumo o gusto musical, lo cual genera ideas de relaciones estáticas y fijas entre música, fenotipo e identidad, y consumo y participación cultural. Para Radano y Bohlman (2000, p. 8), la música «ocupa un lugar entre razas, pero a la vez conserva el potencial de encarnar - $\mathrm{O}$ convertirse - en diferentes significados raciales». 
del álbum. A su vez, la agrupación reconstituida de Juaneco y su Combo también fue invitada a dar conciertos en algunas salas de Lima. Era la primera vez que la música de la Amazonía, frecuentemente ignorada en el contexto de Lima urbana, se oía y bailaba en los sectores de clase alta de la ciudad ${ }^{15}$.

Entrado 2008, no solo la cumbia norteña: la tecnocumbia y la chicha eran ya parte de la cultura popular de la élite limeña, sino también la cumbia amazónica era parte de su universo musical. Bareto demostró que los «colorados» de clase alta eran capaces de ir más allá del consumo pasivo de estos géneros, y de casi ocultar su gusto por ellos. Mostró que también pueden explorar sus sonoridades, bailar al compás de sus ritmos, y sentirlos propios. Es así como algunos jóvenes de las clases altas tradicionales empiezan a transgredir las ideas preexistentes del «buen gusto» y a retar las identidades impuestas por los entornos familiares, lo cual les permite buscarse y encontrarse en el mapa local.

¿Será este aparente cambio en el gusto musical de la clase alta una suerte de «efecto Colón»? (Columbus effect, Valentín Escobar, 2000). Es decir, una especie de orgullo al descubrir lo ya descubierto. Por ejemplo, Bareto indica en las notas del CD Cumbia que su colaboración con Wilindoro y la grabación del álbum fue la forma ideal de documentar su proceso de exploración musical y tributo: «Queríamos mostrarle [a Juaneco] nuestra manera de sentir su música: canciones que eran suyas desde la entraña pero que también, de misteriosa manera, nos pertenecían» (Bareto, Cumbia, 2008). No obstante, en estas mismas notas hay una mención de que el disco es «una reivindicación». Esta mención va de la mano con un reconocimiento abierto de que solo es una reivindicación para una esfera separada en la cual viven los limeños tradicionales. Los integrantes de Bareto buscaron tocar para y con sus ídolos, con el fin de, como ellos dicen, aprender, homenajear y encontrar su identidad a través de una lectura propia de la cumbia de la Amazonía con influencias del rock y Lima, «una sonoridad que iba tomando una identidad propia» (Bareto, Cumbia, 2008).

También podríamos argüir que los fantasmas indigenistas rondan a los músicos fusión y su discurso de rescate, revival y reivindicación de la música tradicional. Sin embargo, Zoila Mendoza (2008) nos recuerda que los procesos de apropiación no son unidireccionales, incluso en el caso de las apropiaciones románticas indigenistas; el proceso es bidireccional, una interacción compleja y de dos vías.

15 Los Andes ocupan un lugar icónico dada la idea romántica del legado incaico, pero la Amazonía ha sido históricamente ignorada y su vez explotada tanto por costeños como por andinos (ver Greene, 2007, 2009, p. 56). 
Es necesario entonces entrar a la experiencia social de los actores para así entender qué pensaron y cómo se sintieron cuando se unieron en el propósito común de «crear lo nuestro» (Mendoza, 2008, p. 181).

Por otro lado, Jonathan Ritter observa que la música híbrida es cómplice de los discursos dominantes de mestizaje - e incluso blanqueamiento-, negando así «la realidad de la discriminación hacia aquellos que no encajan en el molde mestizo nacionalista» (2011, p. 573). Sin embargo, como podemos ver en ejemplos anteriores, la fusión también contribuye al giro de los discursos de mestizaje de proyectos nacionalistas y de asimilación de blanqueamiento a una búsqueda de la «choledad perdida», especialmente entre las clases altas blancas ${ }^{16}$. Además, y como sugiere Peter Wade, «la homogenización existe en una relación compleja y ambivalente con la construcción de diferencia por las mismas fuerzas nacionalistas que crean la homogeneidad» (1998, p. 1).

La interculturalidad pone en evidencia las diferencias y las brechas entre los integrantes de una misma comunidad. Martin Stokes ha notado que la música no une a la gente diversa, sino que la hace aproximarse la una a la otra en acercamientos incómodos y tensos $(1994$, p. 10). Aun así, la música nos hace más conscientes de las brechas imaginadas, y esto puede ser un proceso inicial de toma de conciencia de la diferencia, de entendimiento, aceptación y finalmente autoinclusión, un contexto en el que las tensiones sociales pueden ser negociadas $\mathrm{y}$ transformadas.

\section{DIÁLOGOS MUSICALES: LA MÚSICA FUSIÓN COMO PROCESO DE INTERACCIÓN}

Espero que no se confunda mi énfasis en estudiar las clases altas a través de la música con un deseo ingenuo de atenuar las estructuras de poder o de invisibilizar el privilegio y las jerarquías sociales impulsadas por el neoliberalismo en un país como el Perú. Hoy más que nunca vemos, no solo en el plano local sino mundial, cómo los discursos de odio y de supremacía blanca y de élite surgen en muchas sociedades como la británica o estadounidense. Sin embargo, concuerdo con Peter Wade en que «los valores hegemónicos no se perpetúan de manera automática y autopropulsadas. La gente toma decisiones y escoge no conformarse a estos valores, aunque igual esté informada por ellos» (Wade, 2000, p. 237). Por tanto,

16 La choledad contemporánea representa un mestizaje no asimilativo, una fusión de manifestaciones culturales entre los Andes y la costa, los que crean una identidad chola renovada. 
me parece necesario resaltar las decisiones y expresiones públicas que expresan agencia individual, las cuales forman los sistemas sociales que a veces parecen completamente rígidos e inmutables.

Luego de un primer acercamiento a la estética musical, los músicos fusión tratan de entender los lenguajes musicales que quieren mezclar. Este entendimiento no necesariamente se logra tan solo con comprender la música, sino a través de la participación activa en la cultura que produce dicha música.

Nuestra música tiene que ser un reflejo de la convivencia; esta no es música de escritorio, no es música que está de moda hacerla, no es música que vamos a analizarla y luego sentirla, esto empieza totalmente por la convivencia. Primero se arma un grupo de amigos, se conocen, se visitan, conviven, se entienden (Julio Pérez, La Sarita, entrevista personal, julio 2010).

Mientras esta colaboración se desarrollaba [la de Chocolate Algendones y Manongo], paralelamente se estaba creando una tercera fuerza que ya no era ni mía ni de él, porque si los dos se escuchan de verdad, si yo me pongo a escucharte a ti de verdad y tú te pones a escucharme a mí de verdad, va a haber un tercer elemento que ya no es ni tuyo ni mío y allí se da la magia (Manongo Mujica, entrevista personal, septiembre 2010).

Esto coincide con las ideas de hibridación de Homi Bhabha, esa creación de un «tercer espacio» (1994), «el cual habilita la aparición de otras posiciones (Bhabha citado por Rutherford, 1990, p. 211), un espacio fuera del alcance de los músicos individuales en diálogo, una fuerza independiente. Manongo aquí no solo habla sobre diálogos o encuentros, sino desde ya las fusiones, nuevos lenguajes y conceptos musicales emergen en este tercer espacio. Ricardo Silva resalta el intercambio de conocimientos y el aprendizaje mutuo:

En Del Pueblo del Barrio hay una capacidad y una camaradería [...] los folcloristas han venido a improvisar a Del Pueblo, los criollos a amar el huayno, los afroperuanos a amar el huayno y viceversa, los andinos a aprender el festejo, los rockeros a aprender música peruana y los que tocan música peruana a tener la oportunidad de tocar rock and roll (Ricardo Silva, entrevista personal, diciembre 2010).

La música refleja tensiones y los fusionistas trabajan con ellas a través de la creación de un tercer elemento (Mujica, 2010), logrando una camaradería creativa (Silva, 2010). Frente a la imperante segregación en Lima, esta camaradería representa una negociación musical de diferencia y un espacio para conseguir la autoinclusión. Por ejemplo, el juntar músicos educados en una tradición de música 
clásica occidental con músicos rurales andinos que no leen notas musicales puede fomentar maneras alternativas de componer música (p.e., La Sarita). En La Sarita inicialmente la banda eléctrica se acomodaba a las estructuras andinas creadas por Marino Marcacuzco, pero con el tiempo, Marino empezó a improvisar sobre secuencias de rock y punk. También hay músicos de clases altas que adaptan su estética performativa al lenguaje musical andino. Por ejemplo, María Elena Pacheco acomoda su técnica y posiciones del violín clásico para producir sonidos similares a los del violín andino y corrige su pronunciación del quechua y técnica vocal cuando toca y brinda coros a Magaly Solier, mientras que Colectivo Circo Band usa timbres y texturas para el saxofón que capturan la estética del saxofón en una orquesta típica y banda patronal de los Andes centrales ${ }^{17}$.

Una de las críticas a la hibridación es que alimenta una «ilusión» de bienestar, de que la gente se respeta el uno al otro entendiendo la interculturalidad, de que las clases sociales pueden coexistir, admirarse y respetarse. Aunque parezca idealista, los mismos músicos de fusión en Lima afirman querer alcanzar este fin con su música: verdadera unión en la diversidad y entendimiento intercultural real. En las palabras de Lipsitz, «lo hibrido ofrece una perspectiva desde donde se puede ver más que una sola dirección», «una encrucijada» (1997). Esto permite al público elegir un camino revelado a través de la música. La diferencia no solo es evidenciada y negociada entre músico y audiencia, sino que esta es asumida, internalizada, y en algunos casos encarnada y experimentada por los músicos y luego por el público. Ya no solo como diferencia, sino como algo en común. Todo esto es reforzado por el aspecto visual del performance fusión, ya que en la música popular no se trata solo de lo que escuchamos, sino también de lo que vemos (Katz, 2004, p. 20; Curt Sachs citado por Théberge, 1997, p. 18).

Por ejemplo, Bareto y La Mente utilizan polos que parecen comunes, pero que llevan mensajes políticos sutiles, y a veces no tan sutiles, como una imagen roja del ex presidente del Perú, Alan García, con cuernos; mensajes alusivos al conflicto de Conga o a la reivindicación de la palabra cholo (Cholo is Beautiful), etc. Los miembros de estas bandas usan polos de tiendas o diseñadores particulares, como «Lacraza» (Martín Yépez) y «Faite» (Germán Quino Ganoza - Cherman, José Carlos Carcelén y Samuel Gutiérrez). Germán, de Faite, dice: «lo nuestro es el diseño localista, elegimos un símbolo de nuestra sociedad y lo convertimos

17 Para leer más sobre orquestas típicas, ver Romero (2001). 
en el corazón de una prenda de vestir», así explica sus polos con «sentimiento peruano» (Germán Quino, 2010) ${ }^{18}$.

La popularidad de estos polos entre las clases altas señala un deseo de obtener ese «sentimiento peruano» a través de la aceptación y uso de la estética chicha, una estética previamente rechazada por los sectores altos de la sociedad limeña. El usar estos polos con estéticas andinas, imágenes de Sarita Colonia y Héctor Lavoe, junto con asistir a conciertos fusión, puede interpretarse como una manera de alcanzar «el rico barrio» para vivir una experiencia que los haga sentir incluidos, parte de algo más masivo, más plural; conseguir así respeto y menos antagonismos mediante la recreación de una nueva identidad social a través de la música, una que les permita redimir su culpa histórica (ver Montero-Díaz, 2016).

\section{DONDE OCURRE LA MAGIA: TRASCENDIENDO EL PERFORMANCE}

A través del tercer espacio híbrido (Bhabha, 1994), un espacio «donde ocurre la magia», se encuentra un sentimiento de trascendencia que permite a los fans de la fusión encontrar su propia tradición popular, rituales y significado espiritual y político. Lipsitz (1997) teoriza la hibridación como la oportunidad que tiene el participante de escoger un «camino distinto», cambiando así su yo anterior en búsqueda de algo mejor. Esto se vive como una revelación, una forma de conversión, si no religiosa, social. La Sarita, por ejemplo, junta en sus conciertos a gente de diversas clases sociales y procedencias étnicas. Este grupo mezcla en sus canciones cantos a los apus y al dios católico, indexando rituales andinos y mezclándolos con creencias y realidades de la ciudad.

Soy católico no practicante, mi iglesia es La Noche de Barranco, mi cura son los músicos de fusión, mi confesionario la mesa que me toca [...]. Cada sábado, estoy aquí, la homilía es increíble y practico las enseñanzas mucho mejor que mis amigos cucufatos [mojigatos o puritanos] (Renzo 24 años, entrevista personal, marzo 2011).

Esta comparación entre los conciertos de fusión y la iglesia no es tan rara. Muchos entrevistados escogían metáforas religiosas o espirituales para describir sus emociones como público. Los conciertos de La Sarita, por ejemplo, los describían como una ceremonia religiosa, un lugar donde se congregan, cantan juntos, rezan

18 «Polos con sentimiento», Gestión (03/03/10) http://gestion.pe/noticia/422387/polossentimientoperuano (Visitado noviembre 2016). 
(durante los monólogos de Julio Pérez o con las letras de algunas canciones), aprenden de otros y hallan la motivación para actuar política y socialmente. De nuevo, surge el discurso de la transformación: ¿puede la música facilitar la conversión social? La mayoría de los jóvenes alternativos entrevistados dicen que la música los hace encontrarse a sí mismos y los hace encajar socialmente, ya que sentían no tener identidad local. ¿Puede la fusión trascender el espacio de la música para permitir a las clases altas explorar la peruanidad más allá de sus normalizados roles sociales, jerarquías de clase y construcciones neoliberales de marketing como Marca Perú? En las palabras de Julio Pérez, dirigiéndose a su público:

Agradecemos su presencia el día de hoy y es nuestra esperanza que les hayamos hecho sentir un poquito lo que es una patria, una patria de verdad, más allá de campañas de marketing, que solo son eso. Una patria se construye con vínculos de cariño, con vínculos de respeto, de igualdad. Y cuando alguien quiera abusar de tu compatriota de la selva, de tu compatriota de la sierra, de tu compatriota de mucho más allá de donde tú estás y te indignes, y te moleste y reclames a las autoridades justicia, ese día serás peruano, ese día serás patriota, ese día serás ciudadano peruano (Julio Pérez, La Sarita, Lima Vive Rock, setiembre 2012) ${ }^{19}$.

La Sarita ejemplifica la sacralización del fandom y la participación de una neorreligión a través del consumo de música popular (Hills, 2014). Los entusiastas de La Sarita no son solo seguidores de Julio, el vocalista del grupo, sino que también siguen a cada uno de los once miembros como individuos y a toda la banda como un todo fusionado. Es la incorporación de múltiples símbolos lo que afecta al público, lo que los motiva a buscar su propia identidad trascendiendo la música (ver Hills, 2014). Muchos de los mismos seguidores de La Sarita siguen y son fans de La Mente. Este grupo ha transportado el culto y la transformación personal de los espacios de concierto a las mentes de su público con un llamado a internalizar nuevas creencias y actitudes.

La Mente lanzó su primer álbum en 2007 y se convirtió en una de las bandas favoritas de los alternativos de clase alta. Sus fundadores, Nicolás Duarte y Ricardo Wiesse, se conocieron en un colegio exclusivo de Lima donde empezaron a tocar ska, rock, reggae y cumbia, utilizando secuencias en vivo. Admiraban la música reggae y eran seguidores de muchos músicos rastafarian, asociando el reggae, dub y ska con sonidos peruanos «furtivos», como la chicha y la cumbia amazónica.

19 https://www.youtube.com/watch?v=1mqqmetcFoQ (4.10) (Visitado diciembre 2016). 
Ambos [reggae y cumbia] son música de trópico, música de gente que tiene una historia de opresión, de conquista, música de gente pobre, música de gente que básicamente lo que tiene para decir es o denuncia o lamento (Nicolás Duarte, La Mente, entrevista personal, noviembre 2010).

Muchas de las bandas de fusión fundadas por jóvenes de clase alta comenzaron con covers de reggae o ska. Sin embargo, Nicolás admite que estos géneros son «referentes extranjeros» (entrevista personal, noviembre 2010), entonces, en la fusión muchos jóvenes blancos de clase alta encontraron una manera de «denunciar y lamentar» en términos de reggae, pero usando una estética musical y significantes más peruanos, ubicándose a través de estas estéticas en el mapa peruano. La Mente incluye iconos rastafarians en sus letras (p.e., Babylon), pero las mezclan sincréticamente con cosmovisiones andinas.

¡Es increíble! Cuando escucho a La Mente, me olvido de dónde estoy, solo soy yo y las letras; este momento de reflexión me hace bailar, pero es todo muy personal. Luego abro los ojos y me doy cuenta de que todos están haciendo lo mismo, me siento conectado a toda esta gente, pueden ser diferentes, pero todos somos peruanos. (Mario 24 años, entrevista personal, marzo 2011).

La Mente invita a su público a bailar, pero no en marco de fiesta o baile de pareja: es un baile más individual, y a través de este movimiento personal, hay una conexión con el colectivo.

En el baile hay un sinceramiento corporal que te quita prejuicios, te quita la actitud que puedes tener como público reacio, todo, todo [...] cuando se te empieza a mover el esqueleto no puedes hacer nada (Nicolás Duarte, La Mente, entrevista personal, noviembre 2010).

Al conversar con el público seguidor de La Sarita y La Mente, comúnmente citaban las letras de estos grupos. Las letras de La Mente no son explícitas como las de La Sarita, pero el hecho de que sean más abiertas a diversas interpretaciones permite una experiencia individual menos guiada, más personal.

La Mente es como una religión. Yo me siento un convertido, y como la dice la canción: «ya soy parte de la Mente y aunque mucho me lamente, aquí me voy a quedar» [cantando]. Este cambio es inclusivo, está en mi cabeza, nadie va a cambiar esto, ni mis papás, ni mis amigos, ni mi colegio y mucho menos el presidente de mierda. La revolución empieza con nosotros mismos y termina con nosotros también, pero aún hay muchos pitucos por convertir (Adrián 21 años, entrevista personal, diciembre 2010). 
El impacto de las letras no solo se queda en la música. En junio de 2009, en Bagua-Amazonas, el gobierno peruano ordenó el desalojo violento de aproximadamente cinco mil personas awajún y wampis, y de otros grupos nativos amazónicos que se negaron a ceder sus terrenos a multinacionales mineras. Esta protesta terminó en la masacre conocida como el «baguazo». Hubo cobertura mediática ambigua y mucha discusión académica y política al respecto. La música no se mantuvo ajena: grupos como Bareto y La Mente dedicaron conciertos a los pobladores de Bagua, llamando a sus públicos a reflexionar y protestar activamente contra el gobierno del presidente García Pérez y sus métodos violentos.

Parece ser que la música ha hecho que algunos jóvenes de clase alta se enteren e informen de las necesidades y luchas de aquellos que no forman parte de su círculo social cotidiano, que se indignen y pidan justicia, como pregonaba Julio Pérez en sus conciertos. ¿Están así llenando el vacío de identidad? Bueno, esta conversión musical trasciende el contexto meramente musical y se cristaliza en discursos de nuevas espiritualidades y ciudadanías. Aun así, si el consumo de esta música empezó como una tendencia estética alimentada por deseos idealistas (y hasta ingenuos) de unidad social y transformación personal, esto no excluye ni elimina la existencia de genuinos procesos de pertenencia, en los cuales las clases altas «construyen y actúan posiciones e identidades que los hacen sentir en casa a través de procesos de reflexión» (Savage y otros citado por Longhurst, 2007, p. 49).

El acto de «musicar» (Small, 1998), permite a las clases altas explorar nuevas identidades a través de mecanismos de «pertenencia electiva lo que significa un grado de apertura en las relaciones sociales que otros conceptos tienden a cerrar» (Longhurst, 2007, p. 50). Los espacios de fusión musical constituyen espacios de «pertenencia electiva», donde la fusión ofrece al público un estilo de vida diferente y diversas «relaciones ideales». Esta pertenencia electiva está vinculada con el proceso de «volverse» [becoming], un proceso mediante el cual una persona se conoce a sí misma negociando sus identidades personales y sociales, algo que para Simon Frith sucede en la adultez joven (1987). Esta transformación lenta de hábitos y creencias quizás podría motivar otros cambios en el yo (Turino, 2008).

¿Puede haber un cambio real al transformar los deseos de una vida diferente variando los hábitos de lo cotidiano? La música aquí ofrece una manera de iniciar un cambio personal, una discusión colectiva y luego quizás una acción grupal. La fusión permite a los jóvenes de clases altas tradicionales escapar de la perpetuación automática de los valores hegemónicos heredados y les brinda una oportunidad de mostrar que no se conforman y que desean normalizar otros hábitos. 
A su vez, el proceso de transformación cultural empodera a otros sectores de la sociedad que empiezan a exigir un cambio de hábito social a las clases hegemónicas. Esta conjunción de visiones que retan la hegemonía normalizada puede abrir una oportunidad de diálogo social más plural habilitada por la música.

\section{REFERENCIAS BIBLIOGRÁFICAS}

Bhabha, Homi (1994). The location of culture. Nueva York: Routledge.

Bigenho, Michelle (2012). Intimate Distance: Andean Music in Japan. Durham, DC: Duke University Press. https://doi.org/10.1215/9780822395317

Born Georgina y David Hesmondhalgh (eds.) (2000). Western Music and its Others: Difference, Representation and Appropriation in Music. Berkeley: University of California Press.

De Andrade, Mario (1962 [1928]). Ensaio Sobre a Música Brasileira. São Paulo: Martins. Feld, Steven (2000a). A Sweet Lullaby for World Music. Public Culture, 12(1), 145-171. Winter. Durham NC: Duke University Press. https://doi.org/10.1215/0899236312-1-145

Feld, Steven (2000b). The poetics and politics of Pygmy Pop. En Georgina Born y David Hesmondhalgh (eds.), Western Music and its Others: Difference, Representation and Appropriation in Music (pp. 280-304). Berkeley: University of California Press.

Frith, Simon (1987). Towards an Aesthetic of Popular Music. En Richard Leppert y Susan McClary (eds.), Music and Society: The Politics of Composition, Performance, and Reception (pp. 133-150). Cambridge: Cambridge University Press.

Greene, Shane (2007). Entre lo indio, lo negro, y lo incaico: The Spatial Hierarchies of Difference in Multicultural Peru. Journal of Latin American and Caribbean Anthropology, 12(2), 441-474. American Anthropological Association. https:// doi.org/10.1525/jlat.2007.12.2.441

Greene, Shane (2009). Customizing Indigeneity. Stanford, CA: Stanford University Press.

Hesmondhalgh, David (2000). International times: fusions, exoticisms and antiracism in electronic dance music. En Georgina Born y David Hesmondhalgh (eds.), Western Music and its Others: Difference, Representation and Appropriation in Music (pp. 280-304). Berkeley: University of California Press.

Hills, Matt (2014). Back in the Mix: Exploring Intermediary Fandom and Popular Music Production. En Mark Duffett (ed.), Popular Music Fandom. Identities, Roles and Practices (pp. 16-36). Londres: Routledge. 
Hobsbawm, Eric and Terence Ranger (eds.) (1983). The invention of tradition. Cambridge: Cambridge University Press.

Hopenhayn, Martín (1999). La aldea global entre la utopía transcultural y el ratio mercantil: paradojas de la globalización cultural. En Carlos Iván Degregori y Gonzalo Portocarrero (eds.), Cultura y globalización (pp. 17-35). Lima: Red para el Desarrollo de las Ciencias Sociales en el Perú.

Katz, Mark (2004). Capturing sound. How technology has changed music. Berkeley: University of California Press.

Kisner, Diana (2008). Fusión y discusión: la cumbia peruana está originando un nuevo debate sobre un viejo tema. Cosas (junio), 22-25.

Lipsitz, George (1997 [1994]). Dangerous Crossroads. Popular Music, Postmodernism and the Poetics of Place. Londres: Verso.

Longhurst, Brian (2007). Cultural change and Ordinary Life. Maidenhead, UK: McGraw-Hill / Open University Press.

Mendoza, Zoila S. (2008). Creating our own. Durham NC: Duke University Press. https://doi.org/10.1215/9780822388852

Moehn, Frederick (2012). Contemporary Carioca: Technologies of Mixing in a Brazilian Music Scene. Durham: Duke University Press. https://doi. org/10.1215/9780822394884

Montero-Díaz, Fiorella (2016). Singing the war: reconfiguring white upper-class identity through fusion music in post-war Lima. Ethnomusicology Forum, 25(2), 191-209. https://doi.org/10.1080/17411912.2016.1161528

Radano, Ronald y Philip B. (eds.) (2000). Music and the Racial Imagination. Chicago: University of Chicago Press.

Ritter, Jonathan (2011). Chocolate, Coconut, and Honey: Race, Music and the Politics of Hybridity in the Ecuadorian Black Pacific. Popular Music and Society, 34(5), 571-592. https://doi.org/10.1080/03007766.2010.537848

Romero, Raúl R. (2001). Debating the Past: Music, Memory and Identity in the Andes. Nueva York: Oxford University Press.

Rozas, Efraín(2007). Fusión: banda sonora del Perú. Lima: Instituto de Etnomusicología, PUCP.

Rutherford, J. (1990). The Third Space: Interview with Homi Bhabha. En Jonathan Rutherford (ed.), Identity, Community, Culture, Difference (pp. 207-221). Londres: Lawrence and Wishart.

Slobin, Mark (1993). Subcultural Sounds: Micromusics of the West. Hanover, NH: University Press of New England. 
Small, Christopher (1998). Musicking: the meanings of performing and listening. Londres: Wesleyan University Press, publicado por University Press of New England.

Stokes, Martin (2004). Music and the Global Order. Annual Review of Anthropology, 33, 47-72. https://doi.org/10.1146/annurev.anthro.33.070203.143916

Stokes, Martin (2008). On Musical Cosmopolitanism. Macalester International, 21, $3-26$.

Stokes, Martin (ed.) (1994). Ethnicity, Identity and Music: the musical construction of place. Oxford: Berg Publishers.

Storey, John (2003). Inventing Popular Culture. From Folklore to Globalization. Malden, MA: Blackwell Publishing.

Taylor, Timothy. D. (2003). A Riddle Wrapped in a Mystery: Transnational Music Sampling and Enigma's 'Return to Innocence'. En René T.A. Lysloff y Leslie C. Gay, Jr. (eds.), Music and Technoculture (pp. 64-92). Middletown, CT: Wesleyan University Press.

Théberge, Paul (1997). Any sound you can imagine. Hanover, NH: Wesleyan University Press.

Tucker, Joshua (2013). From the World of the Poor to the Beaches of Eisha. Chicha, Cumbia, and the Search for a Popular Subject in Peru. En H. Fernández L'Hoeste y P. Vila (eds.), Cumbia! Scenes of a Migrant Latin American Music Genre (pp. 138-167). Durham: Duke University Press. https://doi. org/10.1215/9780822391920-007

Turino, Thomas (2008). Music as Social Life. The Politics of Participation. Chicago y Londres: The University of Chicago Press.

Valentin Escobar, Wilson (2000). Marketing memory/Marketing Authenticity in Buena Vista Social Club Recordings. Congreso XXII Latin American Studies Association International Congress LASA, Miami, marzo 16-18.

Wade, Peter (1998). Music, blackness and national identity: Three moments in Columbian history. Popular music, 17(1), 1-19. https://doi.org/10.1017/s0261143000000465

Wade, Peter (2000). Music, Race and Nation: Música tropical in Colombia. Chicago y Londres: University of Chicago Press.

\section{Discografía}

Bareto (2008). Cumbia. PlayMusic\&Video 2000482930545. Perú. 